\title{
Therapeutic results of a novel enzyme-targeting radiosensitization treatment, Kochi oxydol-radiation therapy for unresectable carcinomas II, in patients with stage I primary breast cancer
}

\author{
NOBUTAKA AOYAMA ${ }^{1}$, YASUHIRO OGAWA ${ }^{2}$, MIKI YASUOKA ${ }^{1}$, KENTA OHGI $^{1}$, HITOMI IWASA ${ }^{1}$, \\ KANA MIYATAKE $^{1}$, RIKA YOSHIMATSU ${ }^{1}$, TOMOAKI YAMANISHI ${ }^{1}$, NORIHIKO HAMADA ${ }^{1}$, TAIJI TAMURA ${ }^{1}$, \\ KANA KOBAYASHI $^{1}$, YORIKO MURATA ${ }^{1}$, MITSUHIKO MIYAMURA ${ }^{3}$ and TAKUJI YAMAGAMI ${ }^{1}$ \\ ${ }^{1}$ Department of Diagnostic Radiology and Radiation Oncology, Medical School, Kochi University, \\ Nankoku, Kochi 783-8505; ${ }^{2}$ Hyogo Prefectural Kakogawa Medical Center, Kakogawa, Hyogo 675-0003; \\ ${ }^{3}$ Department of Pharmacy, Medical School Hospital, Kochi University, Nankoku, Kochi 783-8505, Japan
}

Received October 2, 2015; Accepted January 26, 2017

DOI: $10.3892 / 01.2017 .6074$

\begin{abstract}
Linac-based stereotactic radiotherapy has little effect on the majority of advanced neoplasms. Therefore, the novel radiosensitizer Kochi oxydol-radiation therapy for unresectable carcinomas (KORTUC) II, which contains hydrogen peroxide and sodium hyaluronate, was developed. The effectiveness of KORTUC II for the treatment of chemotherapy-resistant supraclavicular lymph node metastases, recurrent breast cancer and stage IV primary breast cancer has previously been demonstrated. The present study evaluated the safety and efficacy of KORTUC II for patients with stage I primary breast cancer. A total of 15 patients (age range, 40-76 years) were enrolled. The injection of $3 \mathrm{ml}$ of KORTUC II agent was initiated from the sixth radiotherapy fraction and was performed twice a week, under ultrasonographic guidance. The therapeutic effects were evaluated by PET-CT and/or MRI examinations prior to and following KORTUC II treatment. All patients exhibited complete responses and the overall survival rate was $100 \%$ after a follow-up period of five years. The mean duration of follow-up at the end of March 2015 was 53 months. Based on these results, KORTUC II
\end{abstract}

Correspondence to: Dr Nobutaka Aoyama, Department of Diagnostic Radiology and Radiation Oncology, Medical School, Kochi University, 203 Kohasu, Okocho, Nankoku, Kochi 783-8505, Japan

E-mail: jm-aoyama_nobutaka@kochi-u.ac.jp

Abbreviation: KORTUC, Kochi oxydol-radiation therapy for unresectable carcinomas

Key words: hydrogen peroxide, sodium hyaluronate, Kochi oxydol-radiation therapy for unresectable carcinomas II, radiosensitizer, stage I primary breast cancer, ultrasonographic guidance treatment exhibited marked therapeutic effects with satisfactory treatment outcomes and an acceptable extent of adverse events.

\section{Introduction}

In the second half of the 20th century, the low sensitivity of medical examination techniques was only able to detect large tumors and advanced-stage cancer, leading to high mortality (1). With the progress of examination techniques, early-stage cancer can now be detected and treated with the development of multidisciplinary therapies. Surgery and radiotherapy are used for local control, whereas chemotherapy is used for systemic control (2-8). The most recent examination techniques occasionally enable the detection of early-stage cancer, oligometastases and oligo-recurrence (9-11). For these forms of cancer, patients may recover completely with multidisciplinary therapy (12-15). However, the majority of cancer types contain numerous hypoxic cells and/or large amounts of antioxidative enzymes and are, therefore, resistant to radiotherapy (16-26). For these types of cancer, the novel radiosensitizer Kochi oxydol-radiation therapy for unresectable carcinomas (KORTUC) II has been developed, the concept of which is presented in Fig. 1 (18-20). Through the use of KORTUC II, hypoxic and radioresistant cancer cells become hyperoxic and radiosensitive, with demonstrable therapeutic effects (16-26). In our previous studies, the effectiveness of KORTUC II for the treatment of supraclavicular lymph node metastases, recurrent breast cancer and stage IV primary breast cancer was demonstrated (18-20). According to the aforementioned strategy, the purpose of this study was to evaluate the safety and efficacy of KORTUC II in patients with stage I primary breast cancer that was not treated with surgery.

\section{Materials and methods}

Patient selection. The present study was performed between January 2008 and April 2013 at the Kochi Medical School Hospital. The Institutional Ethics Committee of the Kochi 
Medical School (Nankoku, Japan) approved KORTUC II for the radiation therapy of stage I primary breast cancer, and 15 female patients were enrolled in the study following the provision of written, informed consent. The inclusion criteria were as follows: The patient requested KORTUC II treatment; the tumor size was $\leq 20 \mathrm{~mm}$; there were no clinical metastases; the patient presented with stage I breast cancer; the presence of contraindications to general anesthesia due to a significant comorbidity, or the patient declined surgical treatment. Patient ages ranged between 40 and 76 years (mean age, 58 years).

To evaluate whether adjuvant therapy was necessary, hormone receptors (estrogen and progesterone), human epidermal growth factor receptor-2, cluster of differentiation 44 and $\mathrm{Ki}-67$ expression status of the tumor were examined using immunohistochemistry in a needle biopsy tissue specimen obtained prior to treatment. In addition, a risk category was assigned to each patient according to the pathological results of the needle biopsy using the updated St. Gallen consensus based on the tumor size (27).

Treatments. Radiotherapy consisted of 44 Gray (Gy) of X-ray irradiation and $9 \mathrm{~Gy}$ of electron boost irradiation. X-ray irradiation consisted of 5 fractions/week at $2.75 \mathrm{~Gy} /$ fraction for a total of 16 fractions, and the X-ray energy level was $4 \mathrm{MeV}$. Electron boost irradiation consisted of 3 fractions of electron beam irradiation at $3 \mathrm{~Gy} /$ fraction, and the electron beam energy level, from 4 to $12 \mathrm{MeV}$, was individually selected for each patient. Tangential irradiation was administered at the target region. KORTUC II consists of $2.5 \mathrm{ml}$ of $1 \% \mathrm{w} / \mathrm{v}$ sodium hyaluronate and $0.5 \mathrm{ml}$ of $3 \% \mathrm{w} / \mathrm{v}$ solution of hydrogen peroxide. Injection of 1.5-3 ml of KORTUC II was initiated at the sixth radiation fraction and was performed twice a week (Monday and Thursday) under ultrasonographic guidance to maintain a high oxygen concentration in the tumor tissue. The combined use of $\sim 0.5 \mathrm{ml}$ of $1 \%$ lidocaine in conjunction with the KORTUC injection was initiated in March 2008, and the amount of KORTUC II administered was adjusted according to the tumor size. The total number of injections was 4-6. Patient data and therapeutic effects are presented in Table I. Following KORTUC II treatment, hormone therapy [leuprorelin acetate (Takeda Pharmaceutical Company, Ltd., Tokyo, Japan): Subcutaneous injection, $3.75 \mathrm{mg}$ every 4 weeks; letrozole (Novartis International AG, Basel, Switzerland): Oral administration, $2.5 \mathrm{mg}$ daily; tamoxifen (AstraZeneca PLC, Cambridge, UK): oral administration, $20 \mathrm{mg}$ daily; or anastrozole (AstraZeneca PLC): oral administration, $1 \mathrm{mg}$ daily] was administered for five years to prevent recurrence, according to the St. Gallen consensus.

Assessment of therapeutic response. The majority of the 15 patients underwent positron emission tomography-computed tomography (PET-CT) and/or dynamic magnetic resonance imaging (MRI) examinations prior to, and 1-7 months following, KORTUC II treatment, and every 6 months thereafter where possible; 12 patients remain available for follow-up at the time of writing. Therapeutic effects were evaluated by comparing the results of pre-treatment and post-treatment PET-CT and MRI examination. The final therapeutic response of the lesion was assessed according to the Revised Response Evaluation Criteria In Solid Tumors (RECIST) guidelines

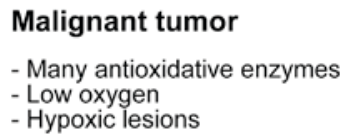

Radioresistant

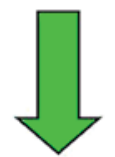

Novel radiosensitizer KORTUC II (sodium hyalurorate containing hydrogen peroxide)

\section{Malignant tumor}

- Reduced antioxidative enzymes

- High oxygen

- Hyperoxic lesions

Figure 1. Mechanism of action of the novel radiosensitizer KORTUC II With KORTUC II treatment, radioresistant tumors become radiosensitive. Adapted from (18-20). KORTUC II, Kochi oxydol-radiation therapy for unresectable carcinomas.

(version 1.1), and patient monitoring and tumor assessment were performed monthly (19). Treatment-associated complications were assessed in detail in order to evaluate the feasibility of this treatment approach by assigning patients a toxicity grade according to the Common Terminology Criteria for Adverse Events (CTCAE criteria; version 4.0) (19). The patient follow-up duration ranged from 25-92 months.

Formulation of KORTUC II. A syringe $(2.5 \mathrm{ml})$ of hyaluronic acid preparation with a $1 \% \mathrm{w} / \mathrm{v}$ concentration of sodium hyaluronate was used for each patient dose. This preparation contained $25 \mathrm{mg}$ of sodium hyaluronate with isotonizing agent (ARTZ Dispo ${ }^{\circledR}$; Seikagaku Corporation, Tokyo, Japan) and $2.5 \mathrm{mg}$ each of L-methionine, sodium chloride, potassium phosphate and crystalline sodium dihydrogen phosphate. The preparation was a colorless, transparent, viscous and aqueous solution, with a $\mathrm{pH}$ of 6.8-7.8, a specific osmotic pressure of 1.0-1.2 (relative to physiological saline) and an average molecular weight of $600,000-1,200,000 \mathrm{~g} / \mathrm{mol}$. A solution $(0.5 \mathrm{ml}$, $3 \% \mathrm{w} / \mathrm{v}$ ) of hydrogen peroxide (Oxydol; Ken-ei Pharmaceutical Co., Ltd., Osaka, Japan) was added immediately prior to use. The solution was mixed well to prepare the radiosensitizer, with a final sodium hyaluronate concentration of $0.83 \%$ and a hydrogen peroxide concentration of $\sim 0.5 \%$. The constituents of the radiosensitizer were the same as those used in previous studies for the treatment of chemotherapy-resistant supraclavicular lymph node metastases, recurrent breast cancer and stage IV primary breast cancer (18-20).

\section{Results}

The KORTUC II treatment was well tolerated with minimal adverse effects. All patients experienced low inflammation at the treatment site, and all were cured by local treatment. The patients were determined to exhibit grade I complications (CTCAE criteria Version 4.0). Although four patients exhibited low liver function impairment 3 months following the start of the KORTUC II radiosensitization treatment, this impairment was also observed prior to treatment in $3 / 4$ of these individuals. Therefore, only 1 patient, patient 9 , who exhibited persistent impairment of liver function as determined by blood examination following treatment with KORTUC II, was 
Table I. Patient data and therapeutic effects of kochi oxydol-radiation therapy for unresectable carcinomas.

\begin{tabular}{|c|c|c|c|c|c|c|c|c|c|c|}
\hline \multirow[b]{2}{*}{ Pt. } & \multirow{2}{*}{$\begin{array}{l}\text { Age, } \\
\text { years }\end{array}$} & \multicolumn{3}{|c|}{ Hormone receptor } & \multirow{2}{*}{$\begin{array}{l}\text { Treatment } \\
\text { region } \\
\text { (RT field) }\end{array}$} & \multirow{2}{*}{$\begin{array}{l}\text { Exposure } \\
\text { dose, Gy }\end{array}$} & \multirow{2}{*}{$\begin{array}{l}\text { Evaluation } \\
\text { method }\end{array}$} & \multirow{2}{*}{$\begin{array}{c}\text { FDG } \\
\text { accumulation }\end{array}$} & \multirow{2}{*}{$\begin{array}{c}\text { Tumor } \\
\text { size, } \mathrm{mm}\end{array}$} & \multirow{2}{*}{$\begin{array}{c}\text { Therapeutic } \\
\text { effect }\end{array}$} \\
\hline & & ER & $\operatorname{PgR}$ & HER2 & & & & & & \\
\hline 1 & 54 & $(+)$ & $(+)$ & $(1+)$ & Left breast & X 44+E9 & PET-CT & $3.9 \rightarrow \mathrm{D}$ & $14 \rightarrow \mathrm{D}$ & $\mathrm{CR}$ \\
\hline 2 & 67 & $(+)$ & $(+)$ & $(-)$ & Right breast & X 44+E9 & PET-CT & $3.2 \rightarrow 1.6$ & $15 \rightarrow D$ & $\mathrm{CR}$ \\
\hline 3 & 46 & $(+)$ & $(+)$ & $(1+)$ & Left breast & X 44+E9 & PET-CT & No data $\rightarrow \mathrm{D}$ & $10 \rightarrow \mathrm{D}$ & $\mathrm{CR}$ \\
\hline 4 & 70 & $(+)$ & $(+)$ & $(-)$ & Right breast & X 44+E9 & PET-CT & No data $\rightarrow \mathrm{D}$ & $7 \rightarrow \mathrm{D}$ & $\mathrm{CR}$ \\
\hline 5 & 48 & $(+)$ & $(+)$ & $(1+)$ & Right breast & X 44+E9 & PET-CT & $5.4 \rightarrow \mathrm{D}$ & $12 \rightarrow \mathrm{D}$ & $\mathrm{CR}$ \\
\hline 6 & 40 & $(+)$ & $(+)$ & $(-)$ & Right breast & X 44+E9 & PET-CT & $2.7 \rightarrow \mathrm{D}$ & $9 \rightarrow \mathrm{D}$ & $\mathrm{CR}$ \\
\hline 7 & 62 & $(+)$ & $(+)$ & $(1+)$ & Right breast & X 44+E9 & PET-CT & No data & $11 \rightarrow \mathrm{D}$ & $\mathrm{CR}$ \\
\hline 8 & 63 & $(+)$ & $(+)$ & $(1+)$ & Right breast & X 44+E9 & PET-CT & $1.9 \rightarrow 1.0$ & $15 \rightarrow D$ & $\mathrm{CR}$ \\
\hline 9 & 76 & $(+)$ & $(+)$ & $(-)$ & Left breast & X 44+E9 & PET-CT & No data $\rightarrow \mathrm{D}$ & $7 \rightarrow D$ & $\mathrm{CR}$ \\
\hline 10 & 43 & $(+)$ & $(+)$ & $(1+)$ & Right breast & X 44+E9 & PET-CT & No data $\rightarrow \mathrm{D}$ & $9 \rightarrow \mathrm{D}$ & $\mathrm{CR}$ \\
\hline 11 & 50 & $(+)$ & $(+)$ & $(2+)$ & Right breast & X 44+E9 & PET-CT & $4.5 \rightarrow \mathrm{D}$ & $20 \rightarrow D$ & $\mathrm{CR}$ \\
\hline 12 & 60 & $(-)$ & $(-)$ & $(2+)$ & Right breast & X 44+E9 & MRI & No data & $18 \rightarrow \mathrm{D}$ & $\mathrm{CR}$ \\
\hline 13 & 61 & $(+)$ & $(+)$ & $(-)$ & Right breast & $\mathrm{X} 44+\mathrm{E} 9$ & MRI & No data & $23 \rightarrow D$ & $\mathrm{CR}$ \\
\hline 14 & 63 & $(+)$ & $(+)$ & $(1+)$ & Right breast & X 44+E 9 & MRI & No data & $13 \rightarrow D$ & CR \\
\hline 15 & 73 & $(+)$ & $(+)$ & $(2+)$ & Left breast & $\mathrm{X} 44+\mathrm{E} 9$ & PET-CT & $1.6 \rightarrow$ no data & $10 \rightarrow \mathrm{D}$ & $\mathrm{CR}$ \\
\hline
\end{tabular}

Pt., patient; RT field, radiation therapy field; ER, estrogen receptor; PgR, progesterone receptor; HER2, human epidermal growth factor receptor type 2; CR, complete response; PR, partial response; PD, progressive disease; X, X-ray; E, Electron beam; D, disappearance; PET-CT, positron emission tomography-computed tomography; MRI, magnetic resonance imaging; Gy, gray.

Table II. Details of KORTUC II treatment and adverse events (1).

\begin{tabular}{|c|c|c|c|c|c|c|c|c|c|c|c|}
\hline \multirow[b]{3}{*}{ Pt. } & \multirow{3}{*}{$\begin{array}{l}\text { Age, } \\
\text { years }\end{array}$} & \multicolumn{3}{|c|}{ Injection of KORTUC II } & \multirow{3}{*}{$\begin{array}{l}\text { Pain } \\
\text { during the } \\
\text { injection }\end{array}$} & \multirow{3}{*}{$\begin{array}{l}\text { Pain on the } \\
\text { next day } \\
\text { of injection }\end{array}$} & \multirow{3}{*}{$\begin{array}{l}\text { Change } \\
\text { of blood } \\
\text { pressure }\end{array}$} & \multirow{2}{*}{\multicolumn{4}{|c|}{ Abnormalities of chest or abdomen }} \\
\hline & & Number & Dose/ & Total & & & & & & & \\
\hline & & of doses & time, $\mathrm{ml}$ & dose, $\mathrm{ml}$ & & & & Pre & Under & Post $\leqq 3 \mathrm{M}$ & Post $>3 \mathrm{M}$ \\
\hline 1 & 54 & 5 & 3 & 15 & $(-)$ & $(-)$ & $(-)$ & $(-)$ & $(-)$ & $(-)$ & $(-)$ \\
\hline 2 & 67 & 5 & 3 & 15 & Low & $(-)$ & $(-)$ & $(-)$ & $(-)$ & $(-)$ & $(-)$ \\
\hline 3 & 46 & 5 & 3 & 15 & Low & $(-)$ & $(-)$ & $(-)$ & $(-)$ & $(-)$ & $(-)$ \\
\hline 4 & 70 & 5 & 3 & 15 & Low & $(-)$ & $(-)$ & $(-)$ & $(-)$ & $(-)$ & $(-)$ \\
\hline 5 & 48 & 5 & 2 & 10 & Low & $(-)$ & $(-)$ & $(-)$ & $(-)$ & $(-)$ & $(-)$ \\
\hline 6 & 40 & 5 & 3 & 15 & $(-)$ & $(-)$ & $(-)$ & $(-)$ & $(-)$ & $(-)$ & $(-)$ \\
\hline 7 & 62 & 5 & 3 & 15 & Low & $(-)$ & $(-)$ & $(-)$ & $(-)$ & $(-)$ & $(-)$ \\
\hline 8 & 63 & 5 & 3 & 15 & $(-)$ & $(-)$ & $(-)$ & $(-)$ & $(-)$ & $(-)$ & $(-)$ \\
\hline 9 & 76 & 5 & 3 & 15 & $(-)$ & $(-)$ & $(-)$ & $(-)$ & $(-)$ & $(-)$ & $(-)$ \\
\hline 10 & 43 & 5 & 1.5 & 7.5 & $(-)$ & $(-)$ & $(-)$ & $(-)$ & $(-)$ & $(-)$ & $(-)$ \\
\hline 11 & 50 & 5 & 1.5 & 7.5 & $(-)$ & $(-)$ & $(-)$ & $(-)$ & $(-)$ & $(-)$ & $(-)$ \\
\hline 12 & 60 & 6 & 3 & 18 & Low & $(-)$ & $(-)$ & $(-)$ & $(-)$ & $(-)$ & $(-)$ \\
\hline 13 & 61 & 6 & 3 & 18 & Low & $(-)$ & $(-)$ & $(-)$ & $(-)$ & $(-)$ & $(-)$ \\
\hline 14 & 63 & 4 & 3 & 12 & Low & $(-)$ & $(-)$ & $(-)$ & $(-)$ & $(-)$ & $(-)$ \\
\hline 15 & 73 & 5 & 3 & 15 & Low & $(-)$ & $(-)$ & $(-)$ & $(-)$ & $(-)$ & $(-)$ \\
\hline
\end{tabular}

Pt., patient; Pre, pretreatment; Under, under treatment; Post, post treatment; M, months; KORTUC II, Kochi oxydol-radiation therapy for unresectable carcinoma.

considered to be a possible candidate for an adverse treatment event. However, no clinical conditions requiring medical treatment were observed as a result of the KORTUC II treatment for any patient. There was no evident mutual association between KORTUC II treatment and the impairment of liver function, and the patient was evaluated as experiencing grade I 
Table III. Details of KORTUC II treatment and adverse events (2).

\begin{tabular}{|c|c|c|c|c|c|c|c|c|c|c|}
\hline \multirow[b]{2}{*}{ Pt. } & \multirow{2}{*}{$\begin{array}{l}\text { Age, } \\
\text { years }\end{array}$} & \multicolumn{4}{|c|}{ Impairment of kidney function } & \multicolumn{4}{|c|}{ Impairment of liver function } & \multirow{2}{*}{$\begin{array}{c}\text { Max value of impairment } \\
\text { of liver function }\end{array}$} \\
\hline & & Pre & Under & Post $\leqq 3 \mathrm{M}$ & Post $>3 \mathrm{M}$ & Pre & Under & Post $\leqq 3 \mathrm{M}$ & Post $>3 \mathrm{M}$ & \\
\hline 1 & 54 & $(-)$ & $(-)$ & $(-)$ & $(-)$ & $(-)$ & $(-)$ & $(-)$ & $(-)$ & $(-)$ \\
\hline 2 & 67 & $(-)$ & $(-)$ & $(-)$ & $(-)$ & $(-)$ & $(-)$ & $(-)$ & $(-)$ & $(-)$ \\
\hline 3 & 46 & $(-)$ & $(-)$ & $(-)$ & $(-)$ & $(-)$ & $(-)$ & $(-)$ & $(-)$ & $(-)$ \\
\hline 4 & 70 & $(-)$ & $(-)$ & $(-)$ & $(-)$ & $(+)$ & $(-)$ & $(+)$ & $(+)$ & $\begin{array}{c}\text { LDH max, 322; CK max, } \\
\text { 449; ALP, } 435\end{array}$ \\
\hline 5 & 48 & $(-)$ & $(-)$ & $(-)$ & $(-)$ & $(-)$ & $(-)$ & $(-)$ & $(-)$ & $(-)$ \\
\hline 6 & 40 & $(-)$ & $(-)$ & $(-)$ & $(-)$ & $(-)$ & $(-)$ & $(-)$ & $(-)$ & $(-)$ \\
\hline 7 & 62 & $(-)$ & $(-)$ & $(-)$ & $(-)$ & $(-)$ & $(-)$ & $(-)$ & $(-)$ & $(-)$ \\
\hline 8 & 63 & $(-)$ & $(-)$ & $(-)$ & $(-)$ & $(-)$ & $(-)$ & $(-)$ & $(-)$ & $(-)$ \\
\hline 9 & 76 & $(-)$ & $(-)$ & $(-)$ & $(-)$ & $(-)$ & $(-)$ & $(+)$ & $(+)$ & CHE max ,562 \\
\hline 10 & 43 & $(-)$ & $(-)$ & $(-)$ & $(-)$ & $(-)$ & $(-)$ & $(-)$ & $(-)$ & $(-)$ \\
\hline 11 & 50 & $(-)$ & $(-)$ & $(-)$ & $(-)$ & $(-)$ & $(-)$ & $(-)$ & $(-)$ & $(-)$ \\
\hline 12 & 60 & $(-)$ & $(-)$ & $(-)$ & $(-)$ & $(+)$ & $(-)$ & $(-)$ & $(+)$ & $\begin{array}{l}\text { AST max, } 40 \\
\text { ALT max, } 67\end{array}$ \\
\hline 13 & 61 & $(-)$ & $(-)$ & $(-)$ & $(-)$ & $(-)$ & $(-)$ & $(-)$ & $(-)$ & $(-)$ \\
\hline 14 & 63 & $(-)$ & $(-)$ & $(-)$ & $(-)$ & $(+)$ & $(+)$ & $(+)$ & $(+)$ & $\begin{array}{l}\text { LDH max, 253; } \\
\text { ALP max, } 529\end{array}$ \\
\hline
\end{tabular}

Pt., patient; Pre, pretreatment; Under, under treatment; Post, post treatment; M, months; Max, maximum; LDH, lactate dehydrogenase; CK, creatine kinase; CHE, cholinesterase; AST, L-aspartate aminotransferase; ALT, L-alanine aminotransferase; ALP, alkaline phosphatase.

A

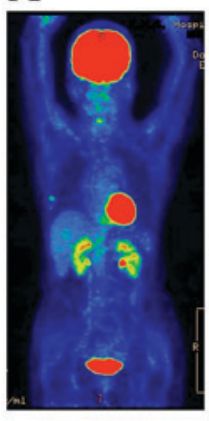

$\mathrm{C}$

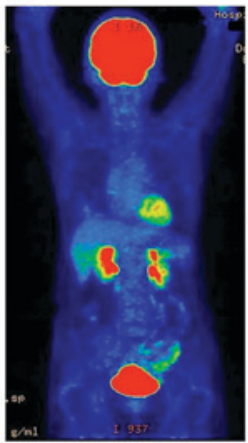

B
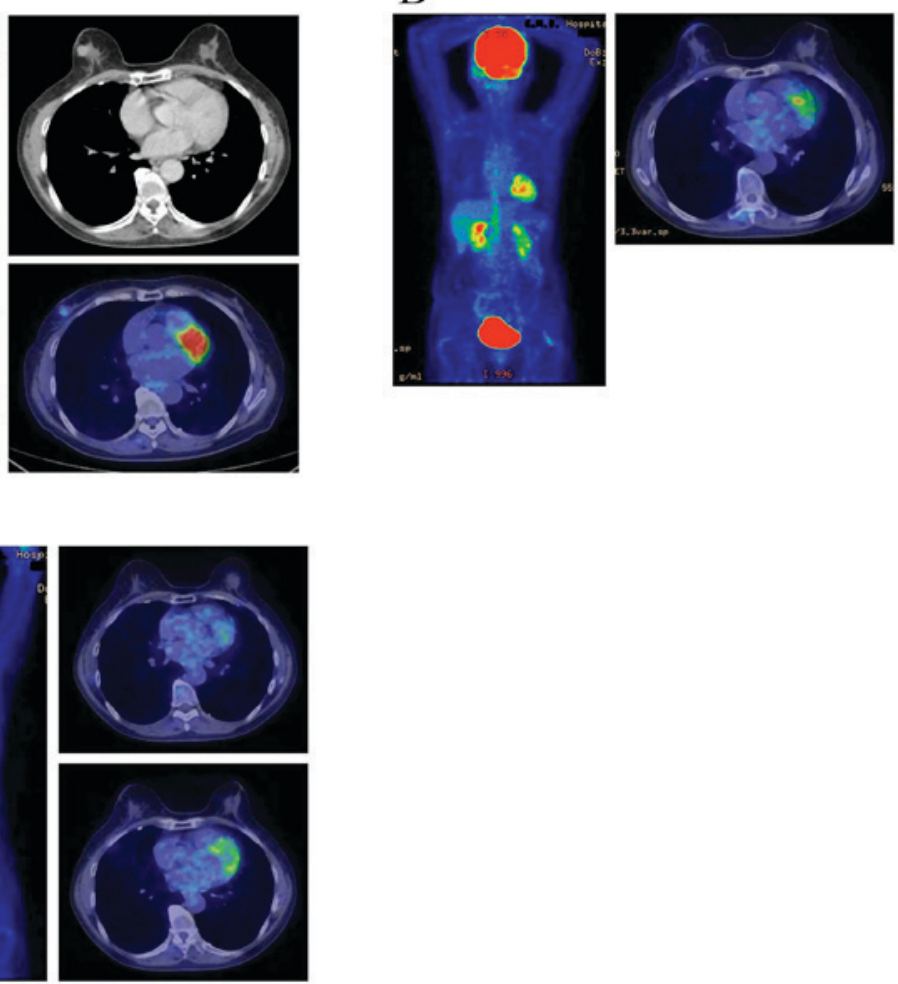

Figure 2. Therapeutic response as evaluated by PET-CT examination in a 67-year-old female with stage I primary right breast cancer (patient 2 in Table I). (A) PET-CT scan image taken immediately prior to KORTUC II treatment. FDG accumulation is visible at the cancerous region of the right breast. The standardized uptake value maximum is 3.2 and the major axis of the cancer is $15 \mathrm{~mm}$. (B) PET-CT scan image taken 7 months following KORTUC II treatment. The target lesion and the FDG accumulation are no longer visible on the CT image. The therapeutic effect was assessed as complete response. (C) PET-CT scan image taken 19 months later. During the follow-up period, local recurrence and metastasis were not observed. PET-CT, positron emission tomography-computed tomography; KORTUC II, Kochi oxydol-radiation therapy for unresectable carcinomas; FDG, fluorodeoxyglucose ${ }^{18}$ F. 
Table IV. Details of cases of impaired liver function.

\begin{tabular}{rcccc}
\hline Pt. & Pre & Under & Post $\leqq 3 \mathrm{M}$ & Post $>3 \mathrm{M}$ \\
\hline 4 & CK max, 449 & $(-)$ & ALP max, 346 & ALP max, 435 \\
& LDH max, 297 & & LDH max, 297 & LDH max, 322 \\
9 & $(-)$ & CHE max, 520 & CHE max, 562 \\
12 & ALT max, 67 & $(-)$ & $(-)$ & ALT max, 45 \\
& AST max, 40 & & AST max, 36 \\
14 & ALP max, 367 & ALP max, 373 346 & ALP max, 529 \\
& & & LDH max, 253
\end{tabular}

Only patients who exhibited impaired liver function are included. Pt., patient; Pre, pretreatment; Under, under treatment; Post, post treatment; M, months; Max, maximum; LDH, lactate dehydrogenase; CK, creatine kinase; CHE, cholinesterase; AST, L-aspartate aminotransferase; ALT, L-alanine aminotransferase; ALP, alkaline phosphatase.
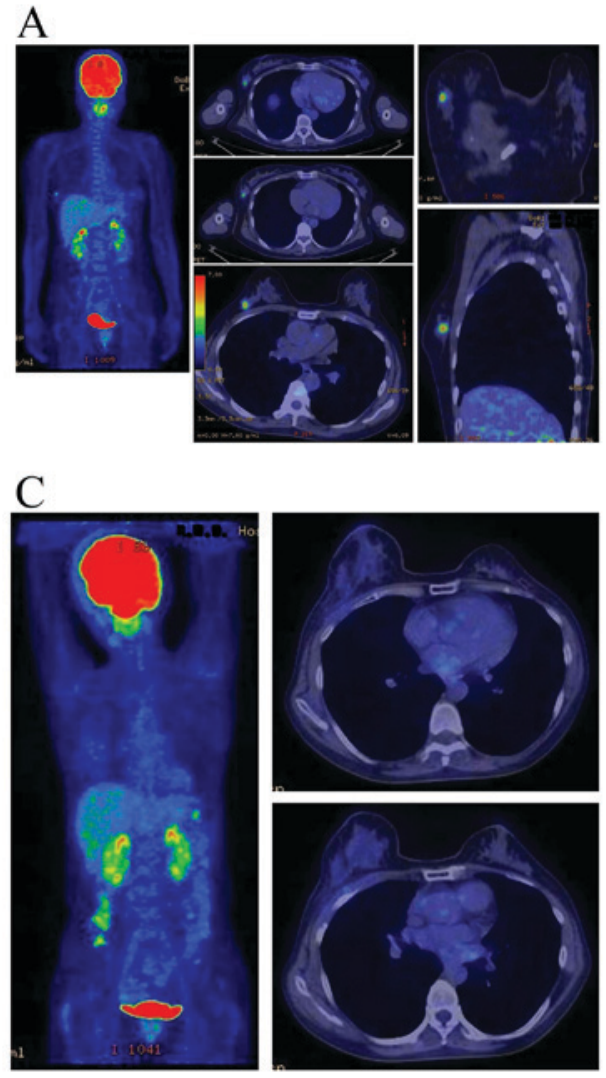

$\mathrm{B}$

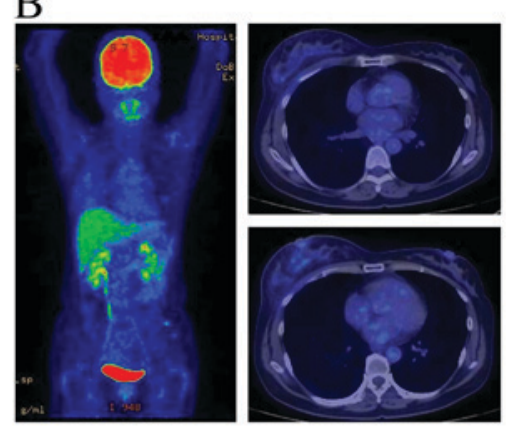

$\mathrm{D}$

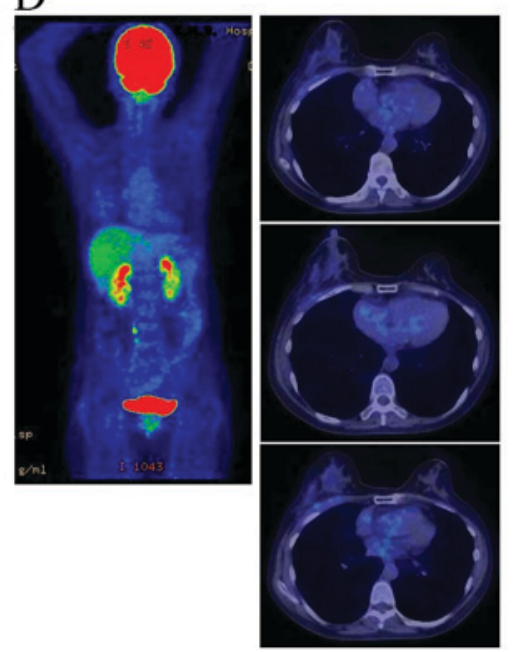

Figure 3. Therapeutic response as evaluated by PET-CT examination in a 48-year-old female with stage I primary left breast cancer (patient 5 in Table I). (A) PET-CT scan image taken immediately prior to KORTUC II treatment. FDG accumulation is visible at the cancerous region of the right breast. The standardized uptake value maximum is 5.4, and the major axis of the cancer is $12 \mathrm{~mm}$. (B) PET-CT scan image taken 9 months following the KORTUC II treatment. The target lesion and the FDG accumulation are no longer visible on the CT image. The therapeutic effect was assessed as complete response (C) PET-CT scan image taken 26 months later. (D) PET-CT scan image taken 38 months following KORTUC II treatment. During the follow-up period, local recurrence and metastasis were not observed. PET-CT, positron emission tomography-computed tomography; KORTUC II, kochi oxydol-radiation therapy for unresectable carcinomas; FDG, fludeoxyglucose ${ }^{18} \mathrm{~F}$.

complications (CTCAE criteria version 4.0). The details of possible adverse events following KORTUC II treatment are presented in Tables II, III and IV.

All lesions exhibited a complete response; the response rate was $100 \%$ and no local recurrence was experienced during the follow-up period. The overall survival rate was $100 \%$ at five years. All patients with estrogen receptor positive tumors (identified in the patient specimens obtained by pre-treatment biopsy) received hormone therapy for 5 years following KORTUC II treatment to prevent recurrence, according to the updated St. Galle consensus. The treatment outcomes were satisfactory and the adverse events were within the acceptable 
range. Images of representative PET-CT examinations are presented in Figs. 2 and 3. The mean follow-up period of the patients at the end of March 2015 was 53 months. No patients succumbed to the disease or exhibited disease recurrence over the course of this study.

\section{Discussion}

At present, the five-year survival rate for stage I breast cancer is $>85 \%$ worldwide $(28,29)$. With the use of multidisciplinary therapy, consisting of limited surgery, hormonal therapy and radiotherapy, the majority of patients with stage I breast cancer can be cured (14). In addition, with the use of radiotherapy following breast-conserving surgery, the rates of local recurrence and mortality have been markedly reduced $(28,29)$. Treatment using the non-surgical method KORTUC II exhibited a response rate of $100 \%$ and an overall 5-year survival rate of $100 \%$ in the present study. At present, the treatment outcomes of KORTUC II are satisfactory, and adverse events, as assessed with visual inspection methods, are within an acceptable range.

The majority of cancer types contain numerous hypoxic cells and/or large quantities of antioxidative enzymes, leading to radiotherapy resistance (16-26). KORTUC II exerts a marked therapeutic effect on these types of cancer. The results of previous studies using KORTUC II to treat supraclavicular lymph node metastasis, recurrent breast cancer and stage IV primary breast cancer were considered to be equal to or improved, compared with the therapeutic results of the commonly-used multidisciplinary therapy administered to patients with advanced conditions originating from primary breast cancer (2-6).

Although the sample size was small in the present study, the positive therapeutic effects of KORTUC II were also reported in previous studies (16-26). Therefore, KORTUC II may be considered as a novel effective therapeutic approach for the treatment of certain types of cancer. KORTUC II consists of sodium hyaluronate and hydrogen peroxide; therefore, this treatment is inexpensive and widely available. In addition, KORTUC II produces positive therapeutic effects and its mechanism of action is simple (Fig. 1). Therefore, the novel radiosensitizer KORTUC II may be used for the treatment of various types of cancer globally. However, prospective randomized clinical trials are required to establish the therapeutic efficacy of KORTUC II.

\section{Acknowledgements}

The authors of the present study would like to thank Forte Science Communications (Tokyo, Japan) for their editorial assistance. The present study was partially supported by a Grant-in-Aid for Scientific Research from the Japanese Ministry of Education, Culture, Sports, Science and Technology (grant no. 25461916).

\section{References}

1. Harris JR: Fifty years of progress in radiation therapy for breast cancer. Am Soc Clin Oncol Educ Book: 21-25, 2014.

2. Danforth DN Jr, Zujewski J, O'Shaughnessy J, Riseberg D, Steinberg SM, McAtee N, Noone M, Chow C, Chaudhry U, Lippman M, et al: Selection of local therapy after neoadjuvant chemotherapy in patients with Stage IIIA, B breast cancer. Ann Surg Oncol 5: 150-158, 1998.
3. Hu XC, Zhang J, Xu BH, Cai L, Ragaz J, Wang ZH, Wang BY, Teng YE, Tong ZS, Pan YY, et al: Cisplatin plus gemcitabine versus paclitaxel plus gemcitabine as first-line therapy for metastatic triple-negative breast cancer (CBCSG006): A randomized, open-label, multicenter, phase 3 trial. Lancet Oncol 16: 436-446, 2015.

4. Karasawa K, Saito M, Hirowatari H, Izawa H, Furuya T, Ozawa S, Ito K, Suzuki T and Mitsuhashi N: The role of chemoradiotherapy in patients with unresectable T4 breast tumors. Breast Cancer 20: 254-261, 2013.

5. Yin $\mathrm{Y}$, Zhang $\mathrm{P}, \mathrm{Xu} \mathrm{BH}$, Zhang BL, Li Q, Yuan $\mathrm{P}$, Cai RG, Wang JY, Wang X and Xu XZ: Unfavorable pathological complete response rate of neoadjuvant chemotherapy epirubicin plus taxanes for locally advanced triple-negative breast cancer. J Huazhong Univ Sci Technolog Med Sci 33: 262-265, 2013.

6. Shaughnessy JN, Meena RA, Dunlap NE, Jain D, Riley EC, Quillo AR and Dragun AE: Efficacy of concurrent chemoradiotherapy for patients with locally recurrent or advanced inoperable breast cancer. Clin Breast Cancer 15: 135-142, 2015.

7. Bollet MA, Sigal-Zafrani B, Gambotti L, Extra JM, Meunier M, Nos C, Dendale R, Campana F, Kirova YM, Diéras V, et al: Pathological response to preoperative concurrent chemo-radiotherapy for breast cancer: Results of a phase II study. Eur J Cancer 42: 2286-2295, 2006.

8. Matuschek C, Bölke E, Roth SL, Orth K, Lang I, Bojar H, Janni JW, Audretsch W, Nestle-Kraemling C, Lammering $\mathrm{G}$, et al: Long-term outcome after neoadjuvant radiochemotherapy in locally advanced noninflammatory breast cancer and predictive factors for a pathologic complete remission: Results of a multivariate analysis. Strahlenther Onkol 188: 777-781, 2012.

9. Niibe Y, Kuranami M, Matsunaga K, Takaya M, Kakita S, Hara T, Sekiguchi K, Watanabe M and Hayakawa K: Value of high-dose radiation therapy for isolated osseous metastasis in breast cancer in terms of oligo-recurrence. Anticancer Res 28: 3929-3932, 2008.

10. Niibe Y and Hayakawa K: Oligometastases and oligo-recurrence: The new era of cancer therapy. Jpn J Clin Oncol 40: 107-111, 2010.

11. Milano MT, Zhang H, Metcalfe SK, Muhs AG and Okunieff P: Oligometastatic breast cancer treated with curative-intent stereotactic body radiation therapy. Breast Cancer Res Treat 115: 601-608, 2009

12. Genet D, Lejeune C, Bonnier P, Aubard Y, Venat-Bouvet L, Adjadj DJ, Martin J, Labourey JL, Benyoub A, Clavère P, et al: Concomitant intensive chemoradiotherapy induction in non-metastatic inflammatory breast cancer: Long-term follow-up. Br J Cancer 97: 883-887, 2007.

13. Mukai H, Watanabe T, Mitsumori M, Tsuda H, Nakamura S, Masuda N, Yamamoto N, Shibata T, Sato A, Iwata H and Aogi K: Final results of a safety and efficacy trial of preoperative sequential chemoradiation therapy for the nonsurgical treatment of early breast cancer: Japan Clinical Oncology Group Study JCOG0306. Oncology 85: 336-341, 2013.

14. Salmon R, Garbey M, Moore LW and Bass BL: Interrogating a multifactorial model of breast conserving therapy with clinical data. PLoS One 10: e0125006, 2015.

15. Massa M, Meszaros P, Baldelli I, Bisso N and Franchelli S: Aesthetic evaluation in oncoplastic and conservative breast surgery: A comparative analysis. Plast Reconstr Surg Glob Open 3: e339, 2015.

16. Ogawa Y, Kubota K, Ue H, Tadokoro M, Matsui R, Yamanishi T, Hamada N, Kariya S, Nishioka A, Nakajima H, et al: Safety and effectiveness of a new enzyme-targeting radiosensitization treatment (KORTUC II) for intratumoral injection for low-LET radioresistant tumors. Int J Oncol 39: 553-560, 2011.

17. Tsuzuki A, Ogawa Y, Kubota K, Tokuhiro S, Akima R, Yaogawa S, Itoh K, Yamada Y, Sasaki T, Onogawa M, et al: Evaluation of changes in tumor shadows and microcalcifications on mammography following KORTUC II, a new radiosensitization treatment without any surgical procedure for elderly patients with stage I and II breast cancer. Cancers (Basel) 3: 3496-3505, 2011.

18. Aoyama N, Ogawa Y, Kubota K, Ohgi K, Kataoka Y, Miyatake K, Tadokoro M, Yamanishi T, Ohnishi T, Hamada N, et al: Therapeutic response to a new enzyme-targeting radiosensitization treatment (KORTUC-SC) for patients with chemotherapy-resistant supraclavicular lymph node metastasis. J Cancer Res Ther 1: 215-219, 2013. 
19. Aoyama N, Ogawa Y, Yasuoka M, Takahashi M, Iwasa H, Miyatake K, Yamanishi T, Hamada N, Tamura T, Nishioka A and Yamagami T: Therapeutic response to a novel enzyme-targeting radiosensitization treatment (Kochi Oxydol-Radiation Therapy for Unresectable Carcinomas) in patients with recurrent breast cancer. Oncol Lett 12: 29-34, 2016.

20. Aoyama N, Ogawa Y, Yasuoka M, Iwasa H, Miyatake K, Yoshimatsu R, Yamanishi T, Hamada N, Tamura T, Kobayashi K, et al: Therapeutic response to a novel enzyme-targeting radiosensitization treatment (KORTUC II) for residual lesions in patients with stage IV primary breast cancer, following induction chemotherapy with epirubicin and cyclophosphamide or taxane. Oncol Lett 13: 69-76, 2017.

21. Ogawa Y, Kubota K, Ue H, Nishioka A, Kariya S, Yokota N Sasaki T, Suzuki K, Nakatani K, Yamanishi T, et al: Development and clinical application of a new radiosensitizer containing hydrogen peroxide and hyaluronic acid sodium for topical tumor injection-a new enzyme-targeting radiosensitization treatment, KORTUC II (Kochi Oxydol-Radiation Therapy for Unresectable Carcinomas, Type II). Strahlenther Onkol 183: 100-101, 2007.

22. Ogawa Y, Ue H, Tsuzuki K, Tadokoro M, Miyatake K, Sasaki T, Yokota N, Hamada N, Kariya S, Hitomi J, et al: New radiosensitization treatment (KORTUC I) using hydrogen peroxide solution-soaked gauze bolus for unresectable and superficially exposed neoplasms. Oncol Rep 19: 1389-1394, 2008.

23. Ogawa Y, Kubota K, Ue H, Kataoka Y, Tadokoro M, Miyatake K, Tsuzuki K, Yamanishi T, Itoh S, Hitomi J, et al: Phase I study of a new radiosensitizer containing hydrogen peroxide and sodium hyaluronate for topical tumor injection: A new enzyme-targeting radiosensitization treatment, kochi oxydol-radiation therapy for unresectable carcinomas, Type II (KORTUC II). Int J Oncol 34: 609-618, 2009

24. Miyatake K, Kubota K, Ogawa Y, Hamada N, Murata Y and Nishioka A: Non-surgical care for locally advanced breast cancer: Radiologically assessed therapeutic outcome of a new-enzyme-targeting radiosensitization treatment, Kochi oxydol-radiation therapy for unresectable carcinomas, type II (KORTUC II) with systemic chemotherapy. Oncol Rep 24: $1161-1168,2010$
25. Tokuhiro S, Ogawa Y, Tsuzuki K, Akima R, Ue H, Kariya S and Nishioka A: Development of a novel enzyme-targeting radiosensitizer (KORTUC) containing hydrogen peroxide for intratumoral injection for patients with low linear energy transfer-radioresistant neoplasms. Oncol Lett 1: 1025-1028, 2010.

26. Hitomi J, Kubota K, Ogawa Y, Hamada N, Murata Y and Nishioka A: Non-surgical therapy and radiologic assessment of stage I breast cancer treatment with novel enzyme-targeting radiosensitization: Kochi Oxydol-radiation therapy for unresectable carcinomas, type II (KORTUC II). Exp Ther Med 1: 769-775, 2010.

27. Gnant M, Thomssen C and Harbeck N: St. Gallen/Vienna 2015: A Brief Summary of the Consensus Discussion. Breast Care (Basel) 10: 124-130, 2015.

28. EORTC Breast Cancer Cooperative Group; EORTC Radiotherapy Group, Bijker N, Meijnen P, Peterse JL, Bogaerts J, Van Hoorebeeck I, Julien JP, Gennaro M, Rouanet P, et al: Breast-conserving treatment with or without radiotherapy in ductal carcinoma-in-situ: Ten-year results of European Organisation for research and treatment of cancer randomized phase III trial 10853-a study by the EORTC breast cancer cooperative group and EORTC radiotherapy group. J Clin Oncol 24: 3381-3387, 2006

29. Early Breast Cancer Trialists' Collaborative Group (EBCTCG), Darby S, McGale P, Correa C, Taylor C, Arriagada R, Clarke M, Cutter D, Davies C, Ewertz M, et al: Effect of radiotherapy after breast-conserving surgery on 10-year recurrence and 15-year breast cancer death: meta-analysis of individual patient data for 10,801 women in 17 randomised trials. Lancet 378: 1707-1716, 2011. 